\title{
Deixis as \\ a Significant Element of Human Communication
}

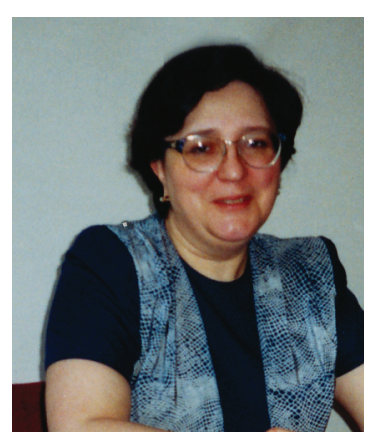

Yelena Yerznkyan

$\mathrm{T}^{\mathrm{s}}$ The continued interest in deixis as a linguistic and cognitive phenomenon proves the fact of its being in the mainstream of linguistic thought. It is widely recognized among linguists that this linguistic category plays a paramount role in the use and understanding of everyday language. Given the great importance of deixis in psychological, philosophical and linguistic approaches to the analysis of language, there has been surprisingly little descriptive work in the area; hence the lack of adequate theory and framework for analysis.

The linguistic phenomenon of deixis is a fundamental element of human communication. Language is directed towards the other. There are two basic speech act roles, the current speaker and hearer/addressee. They are opposed to the others, which are opposed to a negatively defined non-person category. The deictic system grammaticalizes the roles of participants by different means and primarily by pronouns: typically a first person singular pronoun is used for the speaker, second person pronouns for addressee(s) and a third person pronoun for a category 'neither-speaker-nor-addressee(s)'. Speakers use pronouns in order to direct the attention of the addressee to something or someone. Usually this act of reference is an integral part of a speech act, or more generally of a communicative exchange.

The main function of the classes of deictic words in a linguistic system is that of indexing specific aspects of the communication act. Deixis concerns the encoding of many different aspects of the circumstances surrounding the utterance with the utterance itself. Deictic elements link two different kinds of situations: the so-called denotational situation, i.e. what is said in an utterance, to the speech situation, i.e. when, where and by whom they are used, thus encoding both the pragmatic and semantic functions of language. The correlation of these two kinds of situations along different parameters has been repeatedly pointed out by different scholars.

We can say that 'deixis' is the name given to categories of lexicon and grammar that are controlled by certain details of the communicative situation in which the utterances are produced. These details traditionally include the identity of the participants (the speaker and the hearer) in the communicative act, their location and orientation in space, and the time at which the utterance containing the deictic expression is produced. 
While interacting speaker and hearer share a jointly established aim. For understanding to be successful between communicating partners both the speaker and the addressee need to be simultaneously engaged in cognitive processess within which they must be similarly oriented. Deixis assumes a special function in the coordination of cognitive representation: it can be understood as a communicative procedure in which the speaker focuses the attention of the addressee by means of verbal expressions and gestures.

The idea that utterances are basically rooted in the actual speech situation was first systematically developed by Karl Bühler in his classical work on the psychological and linguistic foundations of the theory of deixis (Bühler 1934: 113). In this pioneering work K.Bühler maintains that deictic expressions refer to what he calls the indexical field of language (Zeigfeld der Sprache), whose zero point - the 'origo' in his terminology - is fixed by the person who speaks, by the place of utterance, and by the time of utterance. What deictic expressions refer to is determined by the presently relevant 'origo'.

In recent years the semantics and pragmatics of deixis has become much clearer especially as a result of papers by Charles Fillmore (1966, 1971, 1973, 1975, 1982, 1997) and John Lyons $(1975,1977)$ and others. All contemporary works on deixis are founded on the opposition of the so-called naming words (Nennwörter) and indexing words (Zeigwörter), introduced by Bühler. The significance of his works in the field cannot be overestimated. Still, in our view, K.Bühler's main assumption, that deictical expressions referring to what he calls "indexical field" where the reference point (origo) is fixed by the person who speaks, can be revised.

The most immediately obvious examples of deictics such as pronouns you, this, that, temporal and locative adverbs now, then, here, there, overthere, today, yesterday, tomorrow, such verbs as come and go, bring and take etc. as well as tense forms of the verb speak of the fact that deixis is all-pervasive in the vocabulary and the grammar of natural languages. The principal deictic nature of these words reflects the cognitive representation of the speech event, i.e. the relation between two individuals in a conversation exchange. In order to interpret these elements in a piece of discourse, it is necessary to know (at least) who the interlocutors are, and the time and place of the production of the utterance. Thus, deictics proper constitute the deictic field of language with its three subdivisions of personal deixis, spatial deixis and temporal deixis. Still there is much in language that goes beyond this framework. A great variety of language units, mostly with very abstract meanings have been found to share deictic characteristics although they do not fit into the interlocutors-place-time-of-utterance format (see for details Yerzinkyan 1988).

The characteristic feature of deictics is that they encode a certain type of relation, the relation between the 'origo' and an intended 'referent'. Every act of such reference, i.e. pointing, presupposes a commonly established ground, from which the pointing starts. It is the default assumption that the 'origo' of a pointing act coincides with the speaker of the speech act. However, the 'origo' may be shifted to some other person (or other point in space and time), a process which then has to be marked by certain linguistic means. 
In our research we argue for an extension of Bühler's concept according to which the centre of the deictic field is too narrowly associated with the speaker. Regarding deictic words the main complication to be aware of is that they can also operate relative to a reference point which is not necessarily the actual situation of utterance nor obligatorily the speaker.

Assuming that the 'deictic centre' - the origo - is not always the speaker, deixis is dealt with here from a much broader point of view and covers a far wider range of phenomena including all the notional parts of speech. This can be readily illustrated by analysing the meaning of such lexical units as former, current, remote, distant, late, early, soon, nowaday, prewar, postdate, prepay, contemporary, ex-political and the like. The group of words is not homogeneous, but all of them share the deictic feature of being "situationally anchored", though to a different extent. One may go even further and assume that every language sign may have a potential deictic component. Thus, deixis in its broad sense is "a marking off point" in relation to which persons, objects and events of reality are characterised. The "point of orientation" concept is expanded to take into account the distinct situation of utterance. This "marking off point" (centre of orientation or reference point, or 'origo' in Bühler's terminology) is the central issue in the semantics of deixis. It means that the reference of deictic expressions systematically depends on contextual factors such as the position of the speaker in space and time, etc. At the same time, it should be noted that the centre of orientation of the utterance, based on the speaker's point of view, may be shited in different ways to convey certain meanings.

The meaning of deictic signs is of a very special nature. They are not "empty signs" which acquire sense merely in speech. Deictics have meaning of their own, which is independent from that of non-deictic signs. Personal pronouns "I" and "you", for instance, have a constant and definite meaning, a specific semantic content, i.e. the speech act roles, relating to the speaker and the hearer respectively and constantly alternating with each other. Similarly, "here" is largely determined by the context of the utterance as it usually refers to a place that can be identified in relation to the speaker and the hearer.

The meaning of deictic expressions is very general, broad, abstract, but very definite. Deictics have a stable lexical meaning regardless of the context in which they appear. Their specific abstract meaning is "concretised" in speech by being "anchored" to some reference points in particular contexts. A speaker who uses deictic expressions like "yesterday", "recently", "overthere", "left", "current", "later", etc. refers to certain denotata. The hearer who wants to understand this utterance has to identify the specifically intended denotata of deictics. Solving the identification problem in deictic reference involves primarily the setting of a basic reference point.

Sentences like "I'll come to see you tomorrow" seem to have an open slot that is filled by contextual information. This contextual information may be given by prior verbal expression (anaphora), by succeeding verbal expression (cataphora), by common perception of the actual speech situation, etc. Thus, what deictics refer to is determined by a presently relevant origo which is revealed either on the basis of its "presence" in the 
speaker's or hearer's common perceptual field or of its occurrence in the preceding or following contexts.

What is important about deictics is that they are used to refer to items in a linguistic and non-linguistic context. For instance, "now" and "here" as deictics proper refer more often than not to the "now" and "here" of the time and place of speaking; still they can also be established in terms of times and places referred to in a discourse. Thus, if we are to look for contexts to state the meaning of deictics we have to look at both linguistic and non-linguistic contexts: both are specified as relevant contexts for deictic expressions. However, there are good reasons for a commensurate limitation of linguistic contexts: firstly, the relation between a lexical item and extralinguistic contexts is often mediated by purely linguistic contexts; secondly, any aspect of an extralinguistic context can be in principle mirrored linguistically.

Thus, the main characteristics that distinguishes deixis is its inherent indexical property. That is, this class of language units is distinguished by the fact that the complete and explicit semantic interpretation must include a reference to some point of orientation in the context. Once this is understood, it becomes clear that the basic problem of deixis is the specification of this point of orientation, the latter being the central issue involved in the semantics of deixis. The specific nature of this language phenomenon makes it necessary to establish a consistent method of studying it. The approach that we consider to be appropriate here is a variety of contextual approach: it is assumed that the semantic and pragmatic properties of a lexical item are fully reflected in appropriate aspects of the relations in contrast with actual and potential contexts. be mirrored linguistically.

Proceeding with the establishment of a consistent method of deictic analysis it should be noted that the information conveyed in grammars and dictionaries is far from always being exhaustive. This may be explained by rather complicated character of deictic semantics. That is why we think it necessary for the deictic analysis to carry out experiments in order to find out the semantic and pragmatic conditions, to observe language use in context, varying experimentally the relevant context and to find out which are the situational factors that enter into the rules of use of deictic expressions and which are inherent in their semantics.

To sum up, let us state once again that deictic elements are distinguished by the fact that they can only be completely defined if the relationship of these elements to some point outside of themselves, which is considered to be a deictic centre, is taken into account. This particular class of signs is peculiar in that the reference of each occurrence of a deictic sign is an obligatory part of its semantics. Thus, the meaning of each occurrence of a deictic sign is unique, whereas for non-deictic signs the meaning is normally constant for all occurrences. In most natural languages the majority of utterances are deictically anchored, i.e. they contain linguistic expressions with inbuilt contextual parameters whose interpretation is relative to the context of utterance. Successful deictic reference is embedded in a specific speech event and depends on the participants' (interlocutors') awareness of its constituents. Place, time and person (participant roles) are the constitutive elements of the speech act and all 
languages have deictic means to refer to these entities, though there are differences in the way each language conceptualises and encodes these local, temporal and personal entities.

Languages also vary with respect to the degree to which they grammaticalise or lexicalise social, spatial, and temporal deixis. It is important to realise that even superficially similar languages may differ considerably in various details.

While the general outline of the semantics of deixis seems clear, each language is to be separately examined in the light of variables affecting the big picture. Only then, will more specific universals concerning the syntax, semantics, and pragmatics of deixis come to light.

\section{References:}

1. Bühler, K. (1934) Sprachtheorie: Die Darstellungsfunktion der Sprache. Jena: Fischer.

2. Clark, H. (1996) Using Language. Cambridge: Cambridge University Press.

3. Fillmore, Ch. (1966) Deictic Categories in the Semantics of "Come" // Foundations of Language. Vol. 2, N 3.

4. Fillmore, Ch. (1971) Towards a Theory of Deixis // Working Papers in Linguistics. Vol. 3, N 4.

5. Fillmore, Ch. (1973) May We Come in? // Semiotica, Vol. 9, N 2.

6. Fillmore, Ch. (1975) Santa Cruz Lectures on Deixis. Indiana University Linguistic Club, Mimeo.

7. Fillmore, Ch. (1982) Towards a Descriptive Framework for Spatial Deixis // Speech, Place and Action. Chichester, etc.: John Wiley\& Sons.

8. Fillmore, Ch. (1997) Lectures on Deixis. Stanford, Calif.: CSLI Publ.

9. Fuchs, A. (1993) Remarks on Deixis. Heidelberg: Groos.

10. Weissenbom, J.; Klein W. (ed.) (1982) Here and There: Cross-linguistic Studies in Deixis and Demonstration. Amsterdam, Philadelphia: John Benjamins Publishing Company.

11. Lyons, J. (1975) Deixis as the Source of Reference // Formal Semantics of Natural Language. Cambridge: Cambridge University Press.

12. Lyons, J. (1977) Semantics. London, etc.: Cambridge University Press. Vol. 1-2

13. Rauh, G. (ed.) (1983) Essays on Deixis. Turingen: Gunter Narr.

14. Green, K. (ed.) (1995) New Essays on Deixis: Discourse, Narrative, Literature. Amsterdam: Rodopi.

15. Yerzinkyan,Y. (1988) Deikticheskaya semantika slova. Yerevan: Izd. yerevanskogo gos. universiteta. 


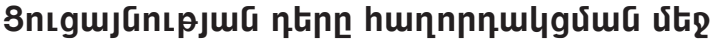

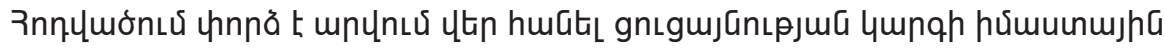

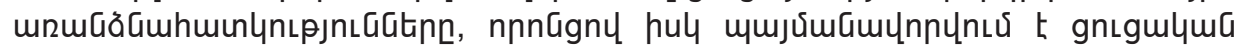

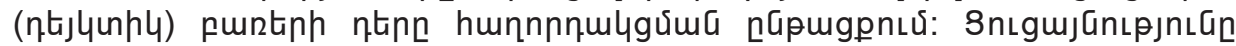

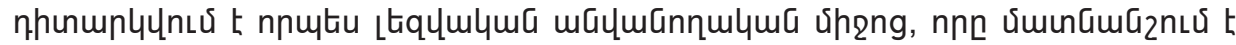

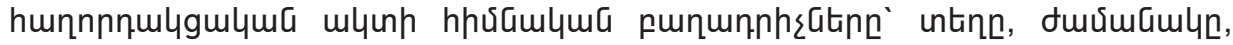

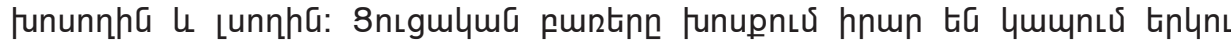

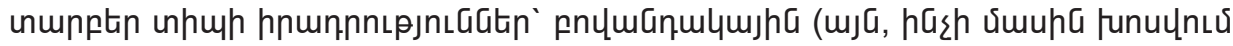

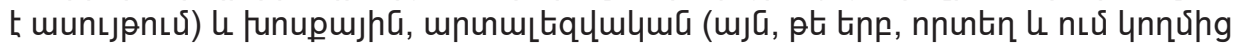

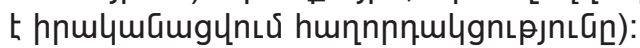

